\title{
Effectiveness of a perioperative pulmonary rehabilitation program following coronary artery bypass graft surgery in patients with and without COPD
}

This article was published in the following Dove Press journal: International Journal of COPD

Jui-O Chen, ${ }^{1,2, *}$ Jui-Fang Liu, ${ }^{1,3-5, *}$ Yu-qi Liu, ${ }^{6}$ Yu-Mu Chen, ${ }^{7}$ Mei-Lien Tu, ${ }^{4}$ Hong-Ren Yu, ${ }^{8}$ Meng-Chih Lin, ${ }^{3,7}$ ChiuChu Lin, ${ }^{2}$ Shih-Feng Liu ${ }^{3,7}$

'Department of Nursing, Tajen University, Pingtung, Taiwan; ${ }^{2}$ College of Nursing, Kaohsiung Medical University, Kaohsiung, Taiwan; ${ }^{3}$ Department of Respiratory Therapy, Kaohsiung Chang Gung Memorial Hospital-Kaohsiung Medical Center and Chang Gung University College of Medicine, Kaohsiung, Taiwan; ${ }^{4}$ Respiratory Care, Chang Gung University of Science and Technology, Taoyuan, Taiwan; ${ }^{5}$ Department of Education, National Kaohsiung Normal University, Kaohsiung, Taiwan; ${ }^{6}$ Department of Intensive Care unit, The Second Affiliated Hospital of Fujian Medical University, Quanzhou, China; ${ }^{7}$ Division of Pulmonary and Critical Care Medicine, Department of Internal Medicine, Kaohsiung Chang Gung Memorial Hospital and Chang Gung University College of Medicine, Kaohsiung, Taiwan; ${ }^{8}$ Department of Pediatrics, Kaohsiung Chang Gung Memorial Hospital, Kaohsiung, Taiwan

*These authors contributed equally to this work
Correspondence: Shih-Feng Liu Division of Pulmonary and Critical Care Medicine, Department of Internal Medicine, Kaohsiung Chang Gung Memorial Hospital and Chang Gung University College of Medicine, \#123, Ta-Pei Road, Niaosong, Kaohsiung 833, Taiwan Tel +88677317123 ext 8199 Fax +886 773224942 Email liuphysico@yahoo.com.tw
Purpose: It is unclear whether the effectiveness of pulmonary rehabilitation program (PRP) after cardiac surgery differs between patients with and without COPD. This study aimed to compare the effectiveness of PRP between patients with and without COPD undergoing coronary artery bypass graft (CABG) surgery.

Patients and methods: We retrospectively included patients who underwent CABG surgery and received 3-week PRP from January 2009 to December 2013. We excluded patients who underwent emergency surgery, had an unstable hemodynamic status, were ventilator dependent or did not complete the PRP. Demographics, muscle strength, degree of dyspnea, pulmonary function and postoperative complications were compared.

Results: Seventy-eight patients were enrolled (COPD group, $n=40$; non-COPD group, $\mathrm{n}=38$ ). Maximal inspiratory pressure (MIP; $-34.52 \mathrm{cmH}_{2} \mathrm{O}$ vs $-43.25 \mathrm{cmH}_{2} \mathrm{O}, P<0.01 ;-34.67 \mathrm{cmH}_{2} \mathrm{O}$ vs $-48.18 \mathrm{cmH}_{2} \mathrm{O}, P<0.01$ ), maximal expiratory pressure (MEP; $32.15 \mathrm{cmH}_{2} \mathrm{O}$ vs $46.05 \mathrm{cmH}_{2} \mathrm{O}$, $P<0.01 ; 37.78 \mathrm{cmH}_{2} \mathrm{O}$ vs $\left.45.72 \mathrm{cmH}_{2} \mathrm{O}, P<0.01\right)$ and respiratory rate $(\mathrm{RR} ; 20.65$ breath/minute vs 17.02 breath/minute, $P<0.01 ; 20.65$ breath/minute vs 17.34 breath/minute, $P<0.01)$ in COPD and non-COPD groups, respectively, showed significant improvement, but were not significantly different between the two groups. Forced vital capacity (FVC; $0.85 \mathrm{~L}$ vs $1.25 \mathrm{~L}, P<0.01$ ), forced expiratory volume in 1 second $\left(\mathrm{FEV}_{1} ; 0.75 \mathrm{~L}\right.$ vs $\left.1.08 \mathrm{~L}, P<0.01\right)$, peak expiratory flow (PEF; $0.99 \mathrm{~L}$ vs $1.79 \mathrm{~L}, P<0.01)$ and forced expiratory flow between $25 \%$ and $75 \%$ of vital capacity $\left(\mathrm{FEF}_{25-75} ; 0.68 \mathrm{~L}\right.$ vs $\left.1.15 \mathrm{~L}, P<0.01\right)$ showed significant improvement between postoperative Days 1 and 14 in the COPD group. FVC $(1.11 \mathrm{~L}$ vs $1.36 \mathrm{~L}, P<0.05), \mathrm{FEV}_{1}(96 \mathrm{~L}$ vs $1.09 \mathrm{~L}$, $P<0.05)$ and $\mathrm{FEF}_{25-75}(1.03 \mathrm{~L}$ vs $1.26 \mathrm{~L}, P<0.05)$ were significantly improved in the non-COPD group. However, only PEF ( $80.8 \%$ vs $10.1 \%, P<0.01)$ and $\mathrm{FEF}_{25-75}(67.6 \%$ vs $22.3 \%, P<0.05)$ were more significantly improved in the COPD group than in the non-COPD group.

Conclusion: PRP significantly improved respiratory muscle strength and lung function in patients with and without COPD who underwent CABG surgery. However, PRP is more effective in improving PEF and $\mathrm{FEF}_{25-75}$ in COPD patients.

Keywords: COPD, coronary artery bypass graft, pulmonary rehabilitation program, pulmonary function, respiratory muscle strength, pulmonary complications

\section{Introduction}

COPD frequently leads to dyspnea and reduced exercise tolerance and significantly affects quality of life. COPD has been the focus of clinical research recently because of its steadily increasing prevalence, mortality and disease burden. Estimates show 
that COPD will become the third leading cause of death worldwide by the year 2030. ${ }^{1}$ In Taiwan, COPD was the seventh leading cause of death in 2013 with a mortality rate of 25.5 per 100,000 and an annual medical cost of 130 million dollars. $^{2}$

COPD is a common comorbid condition in patients who present for coronary artery bypass graft (CABG) surgery. ${ }^{3}$ COPD has been considered a predictor of poor early outcomes in patients undergoing CABG surgery. Patients with moderate-to-severe COPD have a higher risk of mortality $(1.4 \%)$ after CABG surgery than patients without COPD $(0.7 \%) .{ }^{4-6}$ Previous studies have shown that there is a greater benefit of preoperative than postoperative physical therapy in patients undergoing CABG surgery. ${ }^{7,8}$ The incidence of pulmonary complications such as atelectasis, pleural effusion, pneumonia and respiratory failure in patients undergoing $\mathrm{CABG}$ surgery has ranged from $5 \%$ to $73 \%$ in previous reports. ${ }^{9}$ Atelectasis is common in patients undergoing CABG surgery; this may be due to complex factors, including general anesthesia, diaphragmatic dysfunction and postoperative pain. ${ }^{10}$

Dysfunction of respiratory muscles due to surgery may also lead to a decrease in vital capacity (VC), tidal volume and total lung capacity. Therefore, respiratory muscle weakness has been found to be correlated with a higher rate of postoperative pulmonary complications, which may be prevented by preoperative inspiratory muscles training. ${ }^{11,12}$ Pulmonary dysfunction after CABG surgery is also a well-documented complication with a significant decrease in lung volumes, VC and oxygenation, and a drop in the forced expiratory volume in 1 second $\left(\mathrm{FEV}_{1}\right)$, forced $\mathrm{VC}(\mathrm{FVC})$ and functional residual capacity (FRC) by $30 \%-50 \%{ }^{13-16}$

During the 1980s and 1990s, the pulmonary rehabilitation program (PRP) involved non-pharmacologic treatment; the pathophysiological rationale was not clearly understood. More recently, PRP has become evidence based and is an important intervention in patients with COPD to improve muscle tone and reduce disability. ${ }^{17,18}$ Previous studies have demonstrated the effectiveness of pulmonary training in reducing pulmonary complications. Training techniques include preoperative breathing exercises, respiratory muscle training, spirometry training, postoperative bronchial toileting, early ambulation, lung expansion techniques and spirometry training. ${ }^{19,20}$ However, it is unclear whether the effectiveness of PRP after cardiac surgery differs between patients with and without COPD. The purpose of this study was to compare the effectiveness of perioperative PRP in patients with and without COPD who undergo CABG surgery.

\section{Patients and methods}

We retrospectively reviewed patients who underwent $\mathrm{CABG}$ surgery and received perioperative PRP at the Kaohsiung Chang Gung Memorial Hospital, Taiwan, using electronic charts from January 2009 to December 2013 (Figure 1). Patients who underwent emergency surgery, were hemodynamically unstable, were ventilator dependent and had not undergone the full PRP were excluded. We collected data on demographic characteristics, muscle strength, the degree of dyspnea, pulmonary function and postoperative pulmonary complications to compare COPD and non-COPD patients.

\section{PRP}

The PRP included smoking cessation, breathing exercises (pursed-lip breathing, diaphragmatic breathing and cough training) three times per day, upper and lower limb exercises 30 minutes per day, incentive spirometry (Triflow-II) three times per day, intermittent positive pressure breathing 10-15 minutes per day and chest physical therapy four times per day (chest percussion, chest fibrillation and posture drainage by respiratory therapist). The interventions commenced 1 week prior to surgery and continued for 2 weeks postoperatively.

\section{Evaluation of respiratory muscle strength and degree of dyspnea}

We used the modified Borg Scale to evaluate self-perceived degree of dyspnea. Patients rated their degree of dyspnea on a scale of $0-10$, with 0 denoting no breathlessness at all and 10 denoting maximum breathlessness. Maximal inspiratory pressure ( $\mathrm{MIP}, \mathrm{cmH}_{2} \mathrm{O}$ ), maximal expiratory pressure (MEP, $\left.\mathrm{cmH}_{2} \mathrm{O}\right)$ and respiratory rate ( $\mathrm{RR}$, beats/minute) were noted from the charts.

\section{Pulmonary function test}

Participants underwent spirometry to evaluate pulmonary function on Days 1 and 14 postoperatively. The parameters measured included FVC, $\mathrm{FEV}_{1}, \mathrm{FEV}_{1} / \mathrm{FVC}$ ratio, peak expiratory flow (PEF) and forced expiratory flow between $25 \%$ and $75 \%$ of $\mathrm{VC}\left(\mathrm{FEF}_{25-75}\right)$.

\section{Ethics approval and consent to participate}

The study was approved by the Chang Gung Memorial Hospital review board (IRB103-0898C). Although patients' consent to review their medical records was not required by our Institutional Review Board, the patient data were kept confidential. 


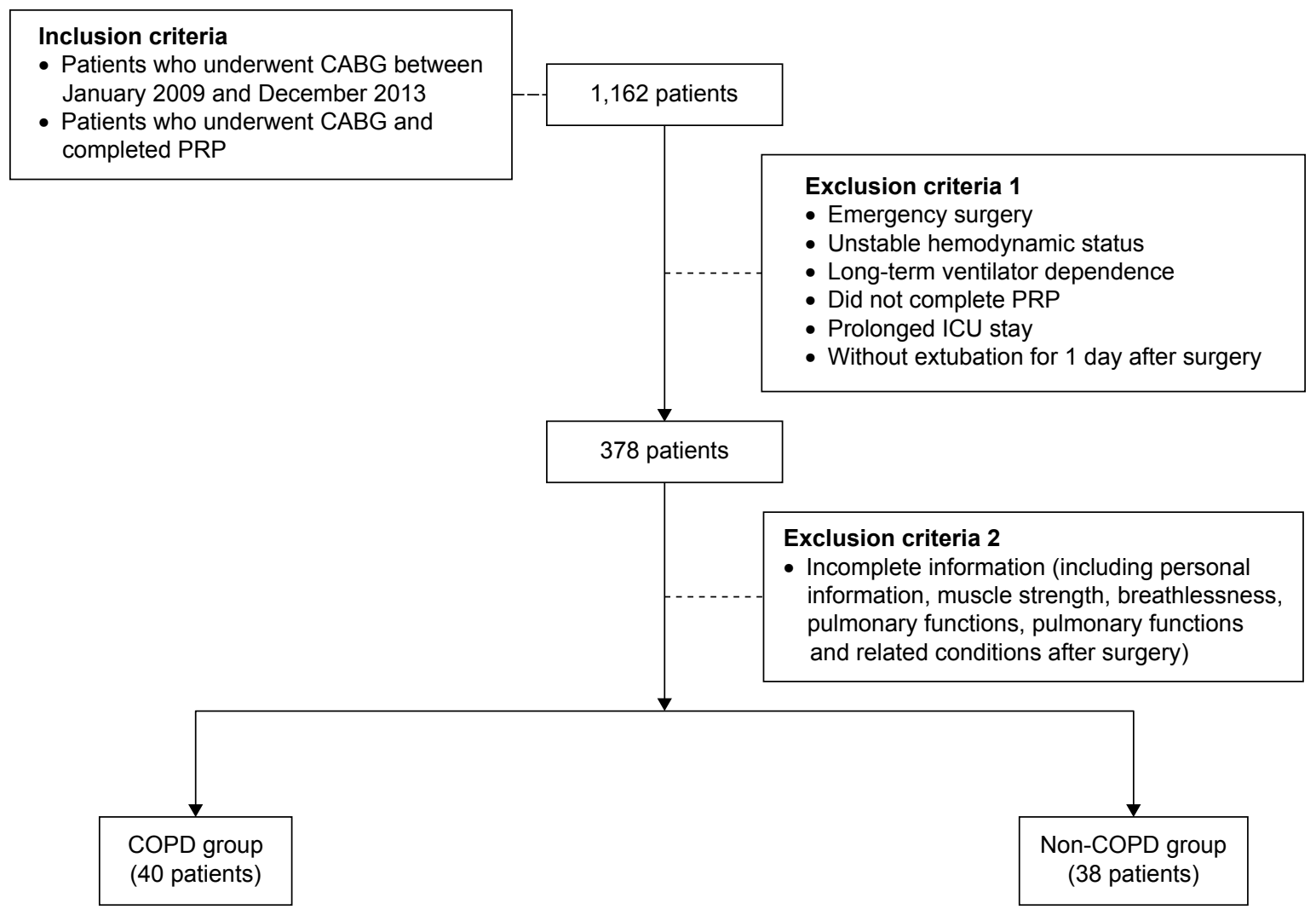

Figure I Overview of patient selection.

Abbreviations: CABG, coronary artery bypass graft; PRP, pulmonary rehabilitation program.

\section{Statistical analysis}

We collected data on Days 1 and 14 postoperatively from electronic charts. Demographic data were analyzed using the chi-square test. A Mann-Whitney $U$-test was used to compare variables on Days 1 and 14 postoperatively. A Wilcoxon signed-rank test was used to compare variables changes on Days 1 and 14 postoperatively between COPD and non-COPD groups. Statistical significance was set at $P<0.05$. All data were analyzed using SPSS 17.0 statistical software.

\section{Results}

We enrolled 78 patients including 40 (51.2\%) who had COPD and $38(48.8 \%)$ who did not.

Table 1 presents the descriptive demographic characteristics of the patients. Age, Acute Physiology and Chronic Health Evaluation II score, American Society of Anesthesiologists physical status, smoking index, comorbidities, preoperative medical therapy, left ventricle ejection fraction, number of coronary artery diseases and surgical types were not significantly different between the groups. There were significantly more male patients $(92.5 \%$ vs $73.7 \%, P<0.05)$ in the COPD group than in the non-COPD group.
Table 2 compares the postoperative respiratory muscle strength and degree of breathlessness between the two groups. MIP $\left(-34.52 \mathrm{cmH}_{2} \mathrm{O}\right.$ vs $-43.25 \mathrm{cmH}_{2} \mathrm{O}$ in the COPD group, $P<0.01 ;-34.67 \mathrm{cmH}_{2} \mathrm{O}$ vs $-48.18 \mathrm{cmH}_{2} \mathrm{O}$ in the non-COPD group, $P<0.01)$, MEP $\left(32.15 \mathrm{cmH}_{2} \mathrm{O}\right.$ vs $46.05 \mathrm{cmH}_{2} \mathrm{O}$ in the COPD group, $P<0.01 ; 37.78 \mathrm{cmH}_{2} \mathrm{O}$ vs $45.72 \mathrm{cmH}_{2} \mathrm{O}$ in the non-COPD group, $\left.P<0.01\right)$ and $\mathrm{RR}$ (20.65 breath/minute vs 17.02 breath/minute in the COPD group, $P<0.01 ; 20.65$ breath/minute vs 17.34 breath/minute in the non-COPD group, $P<0.01)$ showed significant improvement after PRP in both the groups. The improvement of MIP, MEP and RR showed no significant difference between the two groups. The degree of breathlessness on the modified Borg Scale showed no significant improvement in the two groups, and neither was it significantly different between the groups ( 3.10 vs 2.75 in the COPD group, $P>0.05 ; 3.28$ vs 2.94 in the non-COPD group, $P>0.05$ ). A comparison of the postoperative pulmonary function between the two groups is shown in Table 3 and Figure 2. In the COPD group, FVC (0.85 L vs $1.25 \mathrm{~L}, P<0.01), \mathrm{FEV}_{1}(0.75 \mathrm{~L}$ vs $1.08 \mathrm{~L}, P<0.01)$, peak flow $(0.99 \mathrm{~L}$ vs $1.79 \mathrm{~L}, P<0.01)$ and $\mathrm{FEF}_{25-75}(0.68 \mathrm{~L}$ vs $1.15 \mathrm{~L}, P<0.01)$ were significantly higher on postoperative Day 14 compared to postoperative Day 1. 
Table I Patient characteristics

\begin{tabular}{|c|c|c|c|}
\hline Variables & $\begin{array}{l}\text { COPD group } \\
(n=40)\end{array}$ & $\begin{array}{l}\text { Non-COPD } \\
\text { group }(n=38)\end{array}$ & $P$-value \\
\hline Age & & & $0.406^{a}$ \\
\hline$\leq 65$ & $20(50.0 \%)$ & $21(55.3 \%)$ & \\
\hline$\geq 66$ & $20(50.0 \%)$ & $17(44.7 \%)$ & \\
\hline Gender & & & $0.026^{\mathrm{a}, *}$ \\
\hline Male & 37 (92.5\%) & $28(73.7 \%)$ & \\
\hline Female & $3(7.5 \%)$ & $10(26.3 \%)$ & \\
\hline Body mass index $\left(\mathrm{kg} / \mathrm{m}^{2}\right)$ & & & $0.406^{\mathrm{a}}$ \\
\hline$\leq 24$ & $20(50.0 \%)$ & $17(44.7 \%)$ & \\
\hline$\geq 25$ & $20(50.0 \%)$ & 21 (55.3\%) & \\
\hline $\begin{array}{l}\text { Smoking index } \\
\text { (pack-years) }\end{array}$ & $314.63( \pm 567.25)$ & $122.16( \pm 347.14)$ & $0.189^{b}$ \\
\hline APACHE II score & & & $0.449^{a}$ \\
\hline$\leq 13$ & 31 (77.5\%) & $28(73.7 \%)$ & \\
\hline$\geq 14$ & $9(22.5 \%)$ & $10(26.3 \%)$ & \\
\hline ASA physical status & & & $0.069^{a}$ \\
\hline$\leq 3$ & $28(70.0 \%)$ & 34 (89.5\%) & \\
\hline$\geq 4$ & $12(30.0 \%)$ & $4(10.5 \%)$ & \\
\hline Comorbidities & & & $0.188^{\mathrm{a}}$ \\
\hline$\leq 1$ & $16(40.0 \%)$ & $20(54.1 \%)$ & \\
\hline$\geq 2$ & $24(60.0 \%)$ & 18 (45.9\%) & \\
\hline Medical therapy & & & $0.558^{\mathrm{a}}$ \\
\hline Aspirin & 27 (67.5\%) & $20(52.6 \%)$ & \\
\hline Calcium blocker & $2(5.0 \%)$ & $4(10.5 \%)$ & \\
\hline Beta-blocker & $5(12.5 \%)$ & 7 (I8.4\%) & \\
\hline Heparin & $6(15.0 \%)$ & 7 (18.4\%) & \\
\hline Ejection fraction & & & $0.285^{\mathrm{a}}$ \\
\hline$\leq 30$ & $4(10.0 \%)$ & 7 (I8.4\%) & \\
\hline$\geq 30$ & $36(90.0 \%)$ & $31(81.6 \%)$ & \\
\hline Coronary artery disease & & & $0.790^{\mathrm{a}}$ \\
\hline$\leq$ Two-vessel CAD & $10(25.0 \%)$ & $8(21.1 \%)$ & \\
\hline$\geq$ Three-vessel CAD & $30(75.0 \%)$ & $30(78.9 \%)$ & \\
\hline Surgery type & & & $0.679^{a}$ \\
\hline Isolated CABG & $29(72.5 \%)$ & $26(68.4 \%)$ & \\
\hline CABG+aortic valve & $6(15.0 \%)$ & $4(10.5 \%)$ & \\
\hline CABG+mitral valve & $3(7.5 \%)$ & $6(15.8 \%)$ & \\
\hline $\begin{array}{l}\text { CABG+ventricular } \\
\text { septal repair }\end{array}$ & $2(5.0 \%)$ & $2(5.3 \%)$ & \\
\hline \multicolumn{4}{|l|}{ Basal spirometry } \\
\hline $\mathrm{FVC}(\mathrm{L})$ & $2.37( \pm 0.7 \mathrm{I})$ & $2.68( \pm 0.75)$ & $0.093^{b}$ \\
\hline $\mathrm{FEV}_{1}(\mathrm{~L})$ & $1.78( \pm 0.53)$ & $2.22( \pm 0.59)$ & $0.000^{\mathrm{b}, * *}$ \\
\hline $\mathrm{FEV}_{1} \%$ predicted & $69.17( \pm 15.73)$ & $91.08( \pm 13.35)$ & $0.000^{\mathrm{b}, * * *}$ \\
\hline $\mathrm{FEV}_{1} / \mathrm{FVC} \%$ & $67.39( \pm 6.06)$ & $78.51( \pm 8.88)$ & $0.000^{\mathrm{b}, * * *}$ \\
\hline $\mathrm{FEF}_{25-75} \%$ & $50.40( \pm 20.93)$ & $69.19( \pm 14.46)$ & $0.000^{\mathrm{b}, * * *}$ \\
\hline
\end{tabular}

Notes: Comorbidities included diabetes mellitus, chronic kidney disease and hypertension. ${ }^{a} C h i-s q u a r e ~ t e s t . ~{ }^{b} M a n n-W h i t n e y ~ U$-test. $* P<0.05$. $* * P<0.01$.

Abbreviations: APACHE II, Acute Physiology and Chronic Health Evaluation II; ASA, American Society of Anesthesiologists; CAD, coronary artery disease; CABG, coronary artery bypass graft; FVC, forced vital capacity; FEV , forced expiratory volume in I second; $\mathrm{FEF}_{25-75}$, forced expiratory flow between $25 \%$ and $75 \%$.

FVC $(1.11 \mathrm{~L}$ vs $1.36 \mathrm{~L}, P<0.05), \mathrm{FEV}_{1}(96 \mathrm{~L}$ vs $1.09 \mathrm{~L}$, $P<0.05)$ and $\mathrm{FEF}_{25-75}(1.03 \mathrm{~L}$ vs $1.26 \mathrm{~L}, P<0.05)$ were also significantly improved in the non-COPD group. However, peak flow $(80.8 \%$ vs $10.1 \%, P<0.01)$ and $\mathrm{FEF}_{25-75}(67.6 \%$ vs $22.3 \%, P<0.05)$ in the COPD group showed a greater

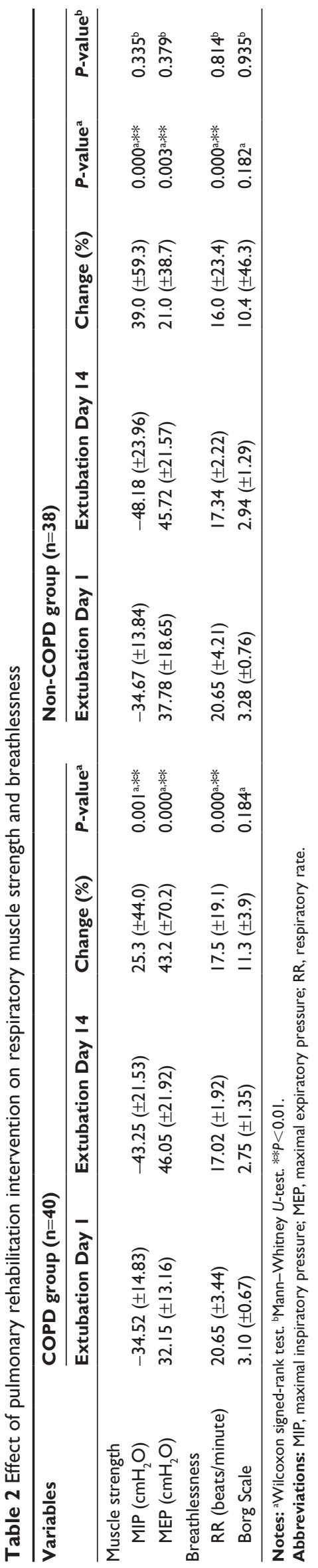




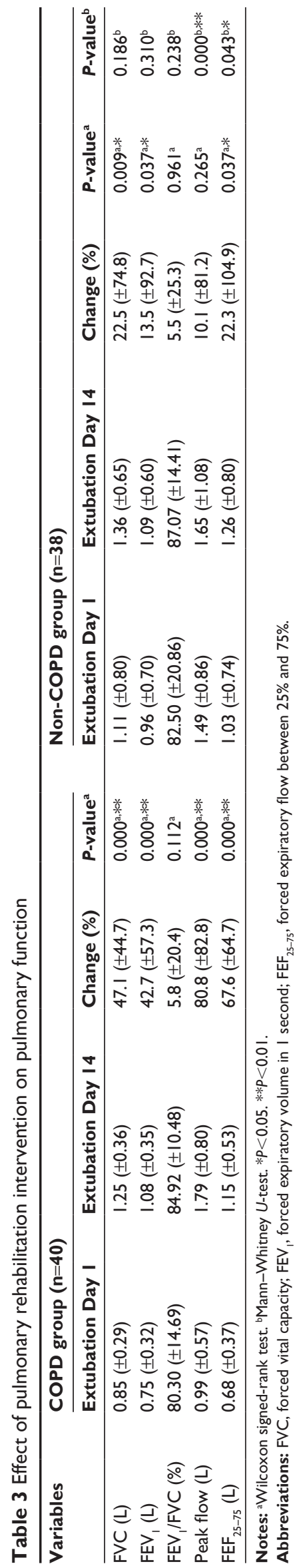

improvement on postoperative Day 14 than on postoperative Day 1 compared to the non-COPD group. For the prevention of gender interference, we only chose male patients for statistical analysis; the results presented in Tables 2 and 3 are similar. Postoperative outcomes are presented in Table 4. The duration for which the chest tube was in place was significantly longer in the COPD group. The duration for which the pericardial drain was in place and duration of mechanical ventilation, ICU stay, hospital stay and oxygen use were not significantly different between the groups. In addition, the 30 -day mortality $(2.4 \%$ vs $2.7 \%, P>0.05)$ and the incidence of postoperative pulmonary complications, including pneumonia $(21.0 \%$ vs $17.5 \%, P>0.05)$, emphysema ( $10.1 \%$ vs $7.8 \%, P>0.05)$ and atelectasis ( $32.5 \%$ vs $31.4 \%, P>0.05)$, were not different between the groups.

\section{Discussion}

Our results demonstrated that patients with and without COPD undergoing CABG surgery with perioperative PRP showed significant improvement in respiratory muscle strength and lung function. However, PEF and $\mathrm{FEF}_{25-75}$ showed more significant improvement in the COPD group than the non-COPD group. Although lung function improvement in the COPD group was not significant compared with the non-COPD group, $\mathrm{FVC}$ and $\mathrm{FEV}_{1}$ showed greater percentage improvement than that in the non-COPD group. It may be due to that COPD patients have worse baseline lung function and respiratory muscle strength compared with non-COPD patients and thus COPD patients have more improvement space. This suggests that perioperative PRP is an important intervention in both COPD and non-COPD patients undergoing $\mathrm{CABG}$ surgery.

COPD is an important risk factor for mortality after CABG surgery. Previous studies have indicated that patients over 65 years of age with COPD have higher morbidity and mortality as well as pulmonary dysfunction after CABG surgery. ${ }^{15,21}$ The degree of pulmonary dysfunction related to lung volumes, $\mathrm{VC}$ and oxygenation is significantly reduced 2 weeks after surgery. ${ }^{13,16}$ Some studies have also found that FVC, $\mathrm{FEV}_{1}$ and FRC drop by $30 \%-50 \%$ during the early postoperative period. ${ }^{13,14,25}$ However, in our study, we found that $\mathrm{FVC}, \mathrm{FEV}_{1}, \mathrm{PEF}$ and $\mathrm{FEF}_{25-75}$ increased significantly in the COPD group after completion of the 3-week PRP. This proved that perioperative $\mathrm{PRP}$ is beneficial for COPD patients undergoing $\mathrm{CABG}$ surgery.

It is well known that $\mathrm{CABG}$ surgery greatly decreases respiratory muscle strength. Hulzebos et $\mathrm{al}^{19}$ showed that preoperative respiratory muscle training could reduce the 


\section{Comparison of postoperative pulmonary functions}

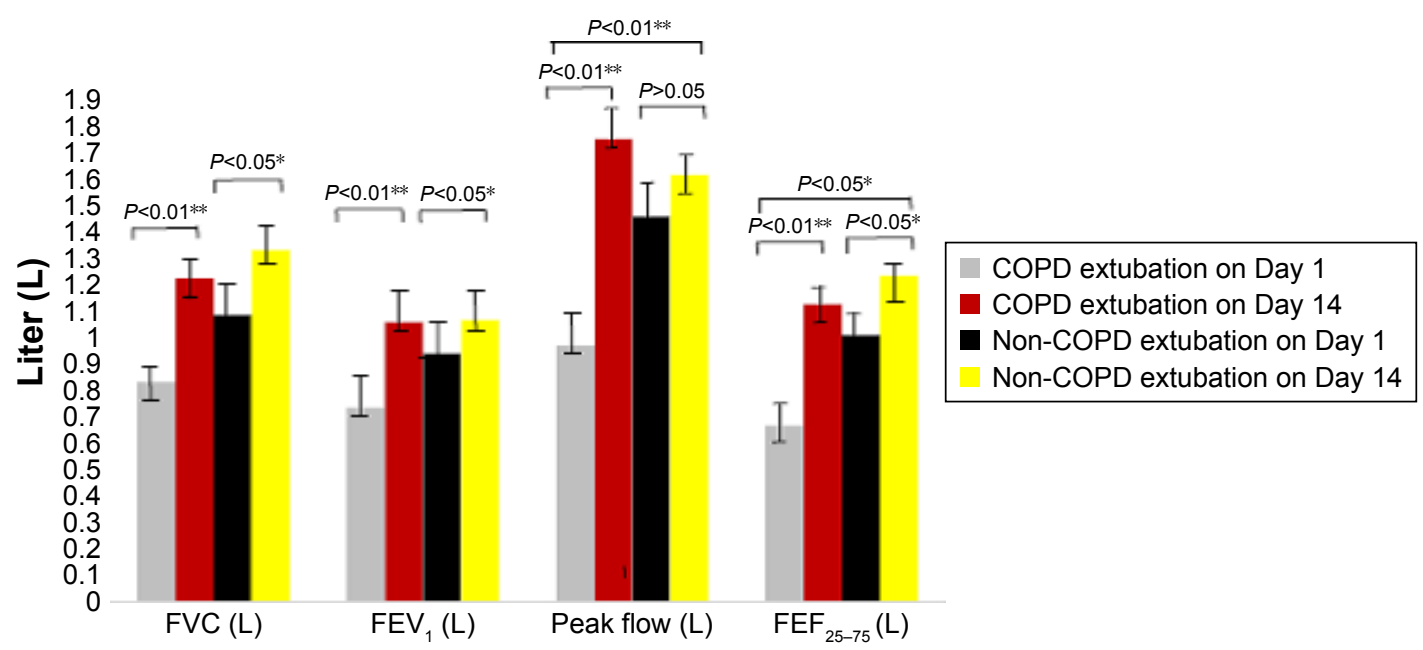

Figure $2 \mathrm{FVC}$, $\mathrm{FEV}_{1}$, peak flow and $\mathrm{FEF}_{25-75}$ on postoperative Days I and 14.

Note: PRP was significantly more effective in improving pulmonary function especially peak flow and $\mathrm{FEF}_{25-75}$ in patients with $C O P D(* P<0.05$, $* * P<0.01)$.

Abbreviations: FVC, forced vital capacity; $\mathrm{FEV}_{1}$, forced expiratory volume in I second; $\mathrm{FEF}_{25-75}$, forced expiratory flow between $25 \%$ and $75 \%$; PRP, pulmonary rehabilitation program.

duration of mechanical ventilation and the incidence of pulmonary complications. Other reports also suggest reduced pulmonary complications with preoperative inspiratory muscle training. ${ }^{11,12,19,22}$ Rajendran et al reported that in patients with COPD undergoing CABG surgery, there was improvement in pulmonary function, reduced atelectasis and

Table 4 Postoperative outcomes in patients with and without COPD

\begin{tabular}{|c|c|c|c|}
\hline Variables & $\begin{array}{l}\text { COPD group } \\
(n=40)\end{array}$ & $\begin{array}{l}\text { Non-COPD } \\
\text { group }(n=38)\end{array}$ & $P$-value \\
\hline Chest tube (hours) & $70.24( \pm 75.20)$ & $14.27( \pm 50.74)$ & $0.000^{\mathrm{a}, * *}$ \\
\hline Pericardial drain (hours) & $163.90( \pm 153.10)$ & $142.66( \pm 95.81)$ & $0.750^{\mathrm{a}}$ \\
\hline Ventilator time (hours) & $33.00( \pm 92.10)$ & $10.52( \pm 8.98)$ & $\left.0.14\right|^{\mathrm{a}}$ \\
\hline ICU time (hours) & $103.07( \pm 56.78)$ & $84.08( \pm 62.78)$ & $0.088^{a}$ \\
\hline $\mathrm{O}_{2}$ use (days) & I I. $44( \pm 3.87)$ & II. $26( \pm 4.76)$ & $0.645^{\mathrm{a}}$ \\
\hline Hospital stay (days) & $23.37( \pm 11.10)$ & $19.80( \pm 7.01)$ & $0.233^{\mathrm{a}}$ \\
\hline 30-Day mortality & & & $0.727^{b}$ \\
\hline No & $39(97.6 \%)$ & 37 (97.3\%) & \\
\hline Yes & I (2.4\%) & I (2.7\%) & \\
\hline \multicolumn{4}{|l|}{ Pulmonary complication } \\
\hline Pneumonia & & & $0.604^{b}$ \\
\hline Yes & $7(17.5 \%)$ & $8(21.0 \%)$ & \\
\hline No & $33(82.5 \%)$ & $30(79.0 \%)$ & \\
\hline Emphysema & & & $0.116^{b}$ \\
\hline Yes & $4(10.1 \%)$ & $3(7.8 \%)$ & \\
\hline No & $36(89.9 \%)$ & 35 (92.29\%) & \\
\hline Atelectasis & & & $0.549^{b}$ \\
\hline Yes & $13(32.5 \%)$ & $12(31.4 \%)$ & \\
\hline No & 27 (67.5\%) & $26(68.6 \%)$ & \\
\hline Respiratory failure & & & $0.388^{b}$ \\
\hline Yes & $4(9.8 \%)$ & $2(5.4 \%)$ & \\
\hline No & $36(90.2 \%)$ & $36(94.6 \%)$ & \\
\hline
\end{tabular}

Notes: aMann-Whitney U-test. ${ }^{\circ}$ Chi-square test. ${ }^{*} * P<0.01$. a shorter duration of ventilation and hospitalization after short-term pulmonary rehabilitation training. ${ }^{7}$ Our study found that respiratory muscle strength had significantly improved on the postoperative Day 14 in both the groups. Besides, the RR decreased in both the groups, with no significant difference in pulmonary complications (pneumonia, emphysema and atelectasis). Thus, our findings corroborate previous reports. We only observed a significantly longer duration of chest tube placement in the COPD group.

Woods et al found that patients with COPD undergoing CABG surgery had significantly higher mortality and pulmonary complications compared to those without COPD. ${ }^{23}$ Postoperative pulmonary dysfunction after $\mathrm{CABG}$ surgery was associated with a longer duration of mechanical ventilation, prolonged hospitalization and higher mortality in a previous study. ${ }^{24}$ In contrast, we did not observe any difference in pulmonary complications and mortality between COPD and non-COPD groups in our study. Thus, PRP is an important perioperative intervention for reducing pulmonary complications and mortality in patients with COPD undergoing CABG surgery.

Our study is limited by its retrospective design; future prospective studies are needed to corroborate our findings. The external validity of our single-center study needs to be established in multicentric studies. Clinical data collection after discharge from hospital and long-term follow-up were not feasible in our retrospective study. We need more prospective studies with more participants with a longer follow-up period to validate our findings. 


\section{Conclusion}

Perioperative PRP interventions significantly improved respiratory muscle strength and lung function in patients with and without COPD who underwent CABG surgery. However, PRP was more effective in improving PEF and $\mathrm{FEF}_{25-75}$ in COPD patients than non-COPD patients. To enhance recovery, a routine administration of perioperative PRP is recommended for patients with COPD and non-COPD who undergo $C A B G$ surgery.

\section{Disclosure}

The authors report no conflicts of interest in this work.

\section{References}

1. WHO [homepage on the internet]. Chronic respiratory disease. 2017 [cited October 20, 2017]. Available from: http://www.who.int/ respiratory/copd/World_Health_Statistics_2008/en/

2. Ministry of Health and Welfare [webpage on the Internet]. 2016 statistics of causes of death. 2017 [cited October 25, 2017]. Available from: https://www.mohw.gov.tw/cp-3327-33592-2.html

3. Decramer M, Janssens W. Chronic obstructive pulmonary disease and comorbidities. Lancet Respir Med. 2013;1(1):73-83.

4. Savas Oz B, Kaya E, Arslan G, Karabacak K, Cingoz F, Arslan M. Pretreatment before coronary artery bypass surgery improves post-operative outcomes in moderate chronic obstructive pulmonary disease patients. Cardiovasc J Afr. 2013;24(5):184-187.

5. Michalopoulos A, Geroulanos S, Papadimitriou L, et al. Mild or moderate chronic obstructive pulmonary disease risk in elective coronary artery bypass grafting surgery. World J Surg. 2001;25(12):1507-1511.

6. Almassi GH, Shroyer AL, Collins JF, et al. Chronic obstructive pulmonary disease impact upon outcomes: the veterans affairs randomized on/off bypass trial. Ann Thorac Surg. 2013;96(4):1302-1309.

7. Rajendran AJ, Pandurangi UM, Murali R, Gomathi S, Vijayan VK, Cherian KM. Pre-operative short-term pulmonary rehabilitation for patients of chronic obstructive pulmonary disease undergoing coronary artery bypass graft surgery. Indian Heart J. 1998;50(5):531-534.

8. Weiner P, Zeidan F, Zamir D, et al. Prophylactic inspiratory muscle training in patients undergoing coronary artery bypass graft. World $J$ Surg. 1998;22(5):427-431.

9. Wynne R, Botti M. Postoperative pulmonary dysfunction in adults after cardiac surgery with cardiopulmonary bypass: clinical significance and implications for practice. Am J Crit Care. 2004;13(5):384-393.

10. Massard G, Wihlm JM. Postoperative atelectasis. Chest Surg Clin N Am. 1998;8:503-528.
11. Siafakas NM, Mitrouska I, Bouros D, Georgopoulos D. Surgery and the respiratory muscles. Thorax. 1999;54:458-465.

12. Vassilakopoulos T, Petrof BJ. Ventilator-induced diaphragmatic dysfunction. Am J Respir Care Med. 2004;169:336-341.

13. Gracey DR, Divertie MB, Didier EP. Preoperative pulmonary preparation of patients with chronic obstructive pulmonary disease: a prospective study. Chest. 1979;76(2):123-129.

14. Hall JC, Tarala RA, Hall JL, Mander J. A multivariate analysis of the risk of pulmonary complications after laparotomy. Chest. 1991;99(4): 923-927.

15. Li C, Yang WH, Zhou J, et al. Risk factors for predicting postoperative complications after open infrarenal abdominal aortic aneurysm repair: results from a single vascular center in China. J Clin Anesth. 2013; 259(5):371-378.

16. McAlister FA, Bertsch K, Man J, et al. Incidence of and risk factors for pulmonary complications after nonthoracic surgery. Am J Respir Crit Care Med. 2005;171(5):514-517.

17. Nici L, Donner C, Wouters E, et al. American Thoracic Society/ European Respiratory Society statement on pulmonary rehabilitation. Am J Respir Crit Care Med. 2006;173:390-1413.

18. Rochester CL, Vogiatzis I, Holland AE, et al. An official American Thoracic Society/European Respiratory Society policy statement: enhancing implementation, use, and delivery of pulmonary rehabilitation. Am J Respir Crit Care Med. 2015;192(11):1373-1386.

19. Hulzebos EH, Smit Y, Helders PP, van Meeteren NL. Preoperative physical therapy for elective cardiac surgery patients. Cochrane Database Syst Rev. 2012;14:11.

20. Shakouri SK, Salekzamani Y, Taghizadieh A, et al. Effect of respiratory rehabilitation before open cardiac surgery on respiratory function: a randomized clinical trial. J Cardiovasc Thorac Res. 2015;7(1):13-17.

21. Smetana GW, Lawrence VA, Cornell JE; American College of Physicians. Preoperative pulmonary risk stratification for noncardiothoracic surgery: systematic review for the American College of Physicians. Ann Intern Med. 2006;144(8):581-595.

22. Powers SK, Wiggs MP, Sollanek KJ, Smuder AJ. Ventilator-induced diaphragm dysfunction: cause and effect. Am J Physiol Regul Integr Comp Physiol. 2013;305(5):R464-R477.

23. Woods SE, Bolden T, Engel A. The influence of chronic obstructive pulmonary disease in patients undergoing coronary artery bypass graft surgery. Int J Med Sci. 2010;2:308-313.

24. Scott BH, Seifert FC, Grimson R, Glass PS. Octogenarians undergoing coronary artery bypass graft surgery: resource utilization, postoperative mortality, and morbidity. J Cardiothorac Vasc Anesth. 2005;19(5): $583-588$.

25. Decramer M, Janssens W, Derom E, et al. Contribution of four common pulmonary function tests to diagnosis of patients with respiratory symptoms: a prospective cohort study. Lancet Respir Med. 2013;1(9): 705-713.
International Journal of COPD

\section{Publish your work in this journal}

The International Journal of COPD is an international, peer-reviewed journal of therapeutics and pharmacology focusing on concise rapid reporting of clinical studies and reviews in COPD. Special focus is given to the pathophysiological processes underlying the disease, intervention programs, patient focused education, and self management protocols.

\section{Dovepress}

This journal is indexed on PubMed Central, MedLine and CAS. The manuscript management system is completely online and includes a very quick and fair peer-review system, which is all easy to use. Visit http://www.dovepress.com/testimonials.php to read real quotes from published authors. 